\title{
Analysis of optimal hedge ratio and hedging effectiveness in Taiwan stock exchange capitalization weighted stock index futures
}

\author{
Jason Aditya Jahja \& IkaYanuarti Loebiantoro \\ Multimedia Nusantara University, Jakarta, Indonesia
}

\begin{abstract}
Theoretically, hedging is effective if there is a balance between the price of asset and price of hedging. The objective of this research was to determine the optimal hedge ratio and hedging effectiveness using Vector Autoregression (VAR) and Vector Error Correction Model (VECM) on TAIEX (Taiwan Stock Exchange Capitalization Weighted Stock Index) Futures. This research provides the conclusion about the more reliable model that can best explain the hedging effectiveness. The daily data were classified into two periods, those are In-Sample Period (January 1st, 2012 - December 31st, 2015) and Out-Sample Period (January 1stDecember 31st, 2016) and were collected on spot and futures index market of TAIEX. The results of this study stated that VECM model provides greater variance reduction compared to the VAR model on both in-sample period and out-of-sample period. The conclusion was a VECM model is more reliable to determine hedging effectiveness for managing the risk.
\end{abstract}

Keywords: hedging effectiveness, optimal hedge ratio, price of asset, price of hedging

\section{INTRODUCTION}

There are several investment alternatives that are available to investors, such as property, gold, foreign currency, bond, stock, and mutual fund. Those investments have different risk level. The higher the return, the higher the risk. However, the investors could manage the risks by entering into a contract of derivative assets, such as forward contract, futures contract, option, and swaps. Each of them has specific characteristics. A futures contract is the most popular derivative nowadays.

An investor could protect his stock investment by entering a futures contract. This risk protection is not directly to the stock but more on a stock index. In Indonesia, the futures contract is traded on Jakarta $\mathrm{Fu}-$ tures Exchange (JFX), through an electronic system. The products of JFX are a futures contract of commodities, currencies, and indexes. Futures contract of the index is on the LQ-45 index. The basic principle of hedging is when the index is predicted to increase then the investors will take a long position in a futures contract. On the other hand, if the index is predicted to decrease then the investors will take a short position. Investors do not have to buy or sell the stock as an underlying asset. It is just a trading in the derivative, rather than underlying asset itself.

In order to be more effective for reducing the risk, the investors should have a better understanding of the type of futures contract, hedge ratio, and effectiveness level of the futures. There are several methods to computing the optimal hedge ratio and hedging effectiveness, such as Ordinary Least Square (OLS) Method, Vector Autoregression (VAR), Vector Error Correction Model (VECM), and Exponentially Weighted Moving Average. Each of the methods gives different percentage value and therefore resulting in different hedging effectiveness.

This research has the objective to analyze and compare the two methods of hedging effectiveness, VAR, and VECM. The object is Taiwan Stock Exchange Capitalization Weighted Stock Index (TAIEX) Futures using two different data period, socalled in-sample and out-of-sample. TAIEX is the index of all listed stock and it is traded in Taiwan Futures Exchange (TAIFEX), which has the relatively high trading volume as compared to other futures exchange.

\section{LITERATURE REVIEW}

\subsection{Hedging Effectiveness}

Ederington (1979) stated that hedging effectiveness is the reduction of variance and the objective of hedging is to minimize the risk. Hedging is said to be effective if R-square in Ordinary Least Square is high, e.g. 90\%. Markowitz (1959) stated that hedging 
effectiveness is the reduction of standard deviation in portfolio return.

\subsection{Previous Research}

Floros \& Vougas (2006) in their research about Hedging Effectiveness on Greek Stock Index Futures Market, 1999-2001, found that R-square using OLS FTSE/ASE-20 is 0.847163 and FTSE/ASE Mid 40 is 0.717509 . It signifies that FTSE/ASE-20 is more effective than FTSE/ASE Mid 40. In-Sample Hedging Effectiveness using OLS method has the highest effectiveness, either in FTSE/ASE-20 or FTSE/ASE Mid 40 compared to the other method. The most effective variance reduction computation is using BGARCH, either for FTSE/ASE-20 and FTSE/ASE Mid 40, 84.695\% and $73.475 \%$ respectively. The methods used in this research are OLS, ECM, VECM, and Bivariate Generalized Autoregressive Conditional Heteroscedasticity (BGARCH).

The computation of hedging effectiveness is also done by Awang et al. (2014) in Malaysia and Singapore futures market. They found that OLS method gives the highest R-square compared to VECM and Exponential Generalized Autoregressive Conditional Heteroskedasticity (EGARCH) and BGARCH. Alexander \& Barbosa (2007) in research about Effectiveness of Minimum-Variance Hedging found something similar. The methods used are OLS, ECM, Exponentially Weighted Moving Average (EWMA), and GARCH.

\subsection{Hypotheses}

The hypotheses of this research are the VECM method resulting better computation of hedging effectiveness than conventional method and VAR method, either for in-sample and out-sample period.

\section{RESEARCH METHODS}

This research is descriptive study of the steps of collecting data, summarizing, describing or analyzing, and representing data informatively. Zikmund et al. (2013) stated that descriptive research is a research that describes characteristics about an object, person, environment.

\subsection{Operational Variables}

There 2 variables used in this paper, including: Spot Price and Futures Price of TAIEX.

\subsubsection{Spot Price}

Definition: the price that is for immediate delivery. In this research we used spot price for the in-sample period, January 1st, 2012 - December 31st, 2015 and out-of-sample period, January 1 st - December 31 st, 2016.

\subsubsection{Futures Price}

Definition: the agreed price of two parties (buyer and seller) of the futures contract for certain settlement date. The futures price is for the in-sample period, January 1st, 2012 - December 31st, 2015 and out-ofsample period, January 1st - December 31st, 2016.

\subsubsection{Spot Price and Futures Price Return}

The return of spot price was computed by the difference spot price $t$ and $t-1$. The return of futures price was computed by the difference futures price $t$ and $t-$ 1 .

\subsection{Technique of Data Analysis}

This analysis used Microsoft Excel and Eviews 9 to estimate econometrics model, VAR, and VECM.

\subsubsection{Test of Stationary}

ADF (Augmented Dickey Fuller Test) used in this research to test if time series data is stationary or not. If the data is not stationary then the result is only applicable in observation time and is not applicable in next period or previous period. It is called spurious regression.

\subsubsection{Test of Cointegration}

Cointegration test is a process to test whether there is a long-term relationship between the two variables. Ghozali (2006) stated that if dependent and independent variables are not stationary but co-integrated then Error Correction Model (ECM) is applicable.

\subsection{Hedge Ratio}

\subsubsection{Vector Autoregression (VAR) method}

This method minimized the problem of autocorrelation between errors and futures price as an endogen variable (Kumar et al. 2008). The data used should be stationary. VAR model is as follows:

$$
\begin{aligned}
& r_{s t}=\alpha_{S}+\sum_{i=1}^{m} \beta_{S i} r_{S t-i}+\sum_{j=1}^{n} \Upsilon_{\mathrm{Fj}} r_{\mathrm{Ft}-\mathrm{j}}+\varepsilon_{S t} \\
& r_{f t}=\alpha_{f}+\sum_{i=1}^{m} \beta_{f i} r_{S t-i}+\sum_{j=1}^{n} \Upsilon_{\mathrm{Sj}} r_{f t-\mathrm{j}}+\varepsilon_{f t}
\end{aligned}
$$


Based on the equation above, error term $\varepsilon s t$ and $\varepsilon \mathrm{ft}$ is an independent identically distributed random vector.

If variance $(\varepsilon s t)=\sigma \mathrm{s}$, variance $(\varepsilon \mathrm{ft})=\sigma \mathrm{f}$ and $c o-$ variance $(\varepsilon s t, \varepsilon f t)=\sigma s f$, then it will be optimal hedge formula:

$$
h^{*}=\frac{\sigma_{s f}}{\sigma_{f}}
$$

Where, $\operatorname{var}(\varepsilon s t)=\sigma \mathrm{s}$

$$
\begin{aligned}
& \operatorname{var}(\varepsilon \mathrm{ft})=\sigma \mathrm{f} \\
& \operatorname{cov}(\varepsilon \mathrm{st}, \varepsilon \mathrm{ft})=\sigma_{\mathrm{sf}}
\end{aligned}
$$

\subsubsection{Vector Error Correction Method (VECM)}

If time series data for spot and futures price, in the long run, is not stationary and have long run integration, then VECM is more precise for computing cointegration spot and futures price in the long run (Lien \& Luo, 1993). The formula of VECM is:

$$
\begin{gathered}
r_{s t}=\alpha_{s}+\sum_{i=1}^{m} \beta_{S i} r_{s t-1}+\sum_{j=1}^{n} \mathrm{y}_{s \mathrm{i}} r_{f \mathrm{t}-1}+\lambda_{s} \mathrm{z}_{\mathrm{t}-1}+\varepsilon_{S t} \\
r_{f t}=\alpha_{f}+\sum_{i=1}^{m} \beta_{f i} r_{S t-i}+\sum_{j=1}^{n} \Upsilon_{f i} r_{f \mathrm{t}-\mathrm{i}}+\lambda_{f} \mathrm{z}_{\mathrm{t}-1}+\varepsilon_{f t}
\end{gathered}
$$

Where, St Ft is natural logarithm of spot and futures price. The formula of optimal hedge ratio is simlar to VAR method.

\subsubsection{Hedging Effectiveness}

Those methods above were inserted in the formula of hedging effectiveness. To make a comparison, the unhedged portfolio will create as same as spot price index. Whereas, the hedged portfolio will create based on a combination of spot and futures price index. (Bhaduri and Durai, 2008) stated that hedging effectiveness (E) computed based on the reduction of variance in hedged portfolio compared to the unhedged portfolio. Return on un-hedged portfolio and hedged portfolio, as follows:

$$
\begin{aligned}
& R_{\text {unhedged }}=S_{t+1}-S_{t} \\
& R_{\text {hedge }}=\left(S_{t+1}-S_{t}\right)-h^{*}\left(F_{t+1}-F_{t}\right)
\end{aligned}
$$

Where, $R_{\text {unhedged }}$ and $R_{\text {hedged }}$ are return for each portfolio. $S_{t}$ and $F_{t}$ are spot and futures price at t period and $h^{*}$ is optimal hedged ratio. Variance of the unhedged and hedged portfolio are as follows:

$$
\begin{aligned}
& \operatorname{Var}_{U}=o_{s}^{2} \\
& \operatorname{Var}_{H}=o_{s}^{2}+h^{* 2} o_{f}^{2}-2 h^{*} o_{S f}
\end{aligned}
$$

Varu and $\operatorname{Var}_{\mathrm{H}}$ are a variance of unhedged and hedged portfolio. $\sigma$ s and $\sigma \mathrm{f}$ are the standard deviation of spot and futures price. $\sigma$ sf is covariant of spot and $f u$ tures. Ederington (1979), hedging effectiveness can be measured by percentage variance reduction on hedged portfolio compare to the unhedged portfolio. The formula for hedging effectiveness $(\mathrm{E})$ is:

$$
\text { Hedging Effectiveness }\left(\ulcorner)=\frac{\left(\operatorname{Var}_{U}-\operatorname{Var}_{H}\right)}{\left(\operatorname{Var}_{U}\right)}\right.
$$

\subsection{Type an Source of Data}

Data in this research was secondary data, and the data consist of:

1. Spot price of TAIEX composite index in period of January 1st, 2012 to December 31st, 2016 from www.finance.yahoo.com

2. Futures price of TAIEX composite index in period of January 1st, 2012 to December 31st, 2016 from www.taifex.com.tw

\section{ANALYSIS OF DATA}

\subsection{The processing stage of data analysis}

The first step is collecting all futures price index data from www.taifex.com.tw. The second step is ensuring the availability of data both in spot and futures price. For instance, on February 4th, 2012 there was only futures price TAIEX available, whereas spot price was not available. The third step is to transform spot and futures price into the 1st difference since these two data are not stationary based on ADF test.

After transforming into the 1 st difference, then the data should be changed to price today and the day before either for spot and futures price.

\subsection{ADF Test}

It is included in unit root test and uses to determine the stationary of data. If the mean and variance are constant then it is stationary and there is no pattern of the mean for dependent and independent variables (Ghozali, 2013). The results of ADF test are as follows:

- The spot price for the $1^{\text {st }}$ difference is stationary. The ADF value for spot price is -34.05 (at $1 \%$ critical value is $-3.44,5 \%$ critical value is 2.86 , and $10 \%$ critical value is -2.57 )

- The futures price for the $1^{\text {st }}$ difference is statinary. The ADF value for spot price is 34.99 (at $1 \%$ critical value is $-3.44,5 \%$ critical value is -2.86 , and $10 \%$ critical value is -2.57 ). 


\subsection{Cointegration Test}

The result is trace statistic value 63.95 which is greater than 0.05 critical value (15.49) and the maxEigen statistic is 59.87 which is greater than 0.05 critical value (14.26). It means that there is a relationship in the long run or there is a cointegration between independent and dependent variables.

\subsection{Optimal Hedge Ratio In-Sample Data}

\subsubsection{VAR Model}

The value of $\sigma s f$ is 4884.32 and the value of $\sigma \mathrm{f}$ is 5375.6 , and therefore the value of $h^{*}$ is 0.908 or $90.8 \%$. The meaning is the investor should buy the futures contract as much as $90.8 \%$ of his total asset value

\subsubsection{VECM}

The value of $\sigma s f$ is 4897.06 and the value of $\sigma \mathrm{f}$ is 5346.62 , therefore $\mathrm{h} *$ is 0.916 or $91.6 \%$.

The meaning is investor should buy futures contract as much as $91.6 \%$ from his total asset value.

\subsection{Hedging Effectiveness (HE) In-Sample Data}

\subsubsection{VAR Model}

The result is Variance Unhedged (Var U) is 4960.48 and Variance Hedged (Var H) is 522.55. Hedging Effectiveness (HE) is 0.8946 or $89.46 \%$ based on VAR model for In-sample data.

\subsubsection{VECM Model}

The result is Variance Unhedged (Var U) is 4993.16 and Variance Hedged (Var H) is 507.86. Hedging Effectiveness (HE) is 0.8982 or $89.82 \%$ based on VECM model for In-sample data.

\subsection{Optimal Hedge Ratio Out-of Sample Data}

\subsubsection{VAR Model}

The covariance value ( $\varepsilon s t \varepsilon f t$ ) is 5674.41 and the value of $\sigma \mathrm{f}$ is 6829.79 , and therefore the value of $h^{*}$ is 0.8308 or $83.08 \%$. The meaning is the investor should buy the futures contract as much as $83.08 \%$ of his total asset value.

\subsubsection{VECM Model}

The covariance value ( $\varepsilon s t \varepsilon f t$ ) is 5767.46 and the value of $\sigma \mathrm{f}$ is 6883.29 , and therefore the value of $h^{*}$ is 0.8378 or $83.78 \%$. The meaning is the investor should buy the futures contract as much as $83.78 \%$ of his total asset value.

\subsection{Hedging Effectiveness Out-of-Sample Data}

\subsubsection{VAR Model}

The result is Variance Unhedged (Var U) is 5181.03 and Variance Hedged (Var H) is 466.54. Hedging Effectiveness (HE) is 0.9099 or $90.99 \%$ based on VAR model for Out-0f-sample data.

\subsubsection{VECM Model}

The result is Variance Unhedged (Var U) is 5289.33 and Variance Hedged (Var H) is 456.81. Hedging Effectiveness (HE) is 0.9136 or $91.36 \%$ based on VAR model for Out-0f-sample data.

Based on the comparison of the method using insample, it can be concluded that VECM has a better measurement of hedging effectiveness than VAR. The reduction in risk is $89.83 \%$ by using VECM as compared to VAR $(89.46 \%)$. While using out-ofsample data, the result is that VECM has a better measurement of hedging effectiveness than VAR. The reduction in risk is $91.36 \%$ by using VECM as compared to VAR (90.99\%).

\section{CONCLUSION}

The conclusion is investor should use futures contract for TAIEX based on VECM model in the out-of-sample period as much as $83.78 \%$ from total asset value. The reason is out-of-sample period is shorter than an in-sample period. It is confirmed that futures contract is also for a short-term period (one up to three months period).

VECM is better than VAR model either in-sample or out-of-sample data, meaning that VECM gives the more stable hedging effectiveness so that it will be a benchmark for risk manager in reducing the risk.

\section{REFERENCES}

Alexander, C., \& Barbosa, A. 2007. Effectiveness of MinimumVariance Hedging. The Journal of Portfolio Management 33(2): 46-59

Awang, N., Azizan, N. A., Ibrahim, I., \& Said, R. M. 2014. Hedging Effectiveness Stock Index Futures Market: An Analysis on Malaysia and Singapore Futures Markets. Proc. International Conference on Economics, Management and Development, Interlaken, 22-24 February 2014. Switzerland: Springer.

Bhaduri, S. N., \& Durai, S. R. 2008. Optimal Hedge Ratio and Hedging Effectiveness of Stock Index Futures: Evidence from India. Macroeconomics and Finance in Emerging Market Economies 1(1): 121-134.

Ederington, L. H. 1979. The Hedging Performance of the New Futures Market. The Journal of Finance 34(1):157-170. 
Floros, C., \& Vougas, D. V. 2006. Hedging Effectiveness in Greek Stock Index Futures Market, 1999-2001. Journal of Finance and Economics 5:7-18.

Ghozali, I., \& Ratmono D. 2006. Analisis Multivariate Lanjutan Dengan Program SPSS. Semarang: Universitas Diponegoro.

Ghozali, I., \& Ratmono D. 2013. Analisis Multivariate dan Ekonometrika Teori, Konsep, dan Aplikasi dengan Eviews 8. Semarang: Universitas Diponegoro.

Kumar, B., Signh, P., \& Pandey, A. 2008. Hedging Effectiveness of Constant and Time Varying Hedge Ratio in Indian Stock and Commodity Futures Markets. Retrieved from https://ssrn.com/abstract=1206555

Lien, H. D., \& Luo, X. 1993. Estimating multiperiod hedge ratios in cointegrated markets. The Journal of Futures Markets 13(8): 909-920.

Markowitz, H.M. 1959. Portfolio Selection: Efficient Diversification of Investments. New York: John Wiley \& Sons, Inc.

Zikmund, W., Babin, B., Carr, J. \& Griffin, M. 2013. Business research methods. 9th ed. Mason, Ohio: South-Western. 